\title{
MESTRES D'OBRA, MESTRES DE CASES E IMAGINAIRES: LA SEMÁNTICA DE LA CONSTRUCCIÓN A FINALES DE LA EdAd MEdia en El CONTEXTO LINGÜÍSTICO CATALÁN
}

\author{
Víctor DANIEl LÓPEZ LORENTE ${ }^{1}$ \\ Universidad de Valladolid
}

Recibido: 3 de mayo de 2020

Aceptado: 1 de junio de 2020

\begin{abstract}
Resumen
A través de este artículo se pretende analizar la semántica de la arquitectura a finales de la Edad Media, partiendo de ejemplos fundamentalmente de los ámbitos catalán y valenciano. En primer lugar, se someten a examen términos que con frecuencia son usados como sinónimos, como mestre d'obres, mestre de cases, e imaginaire, y otros menos habituales como los de arquitecto y aparejador, que esclarecen una realidad edilicia compleja. El análisis de la documentación permite ahondar en la versatilidad de los constructores medievales, comprender el prestigio que alcanzaron determinados artífices, y las relaciones que establecieron con otros oficios cercanos.
\end{abstract}

\section{Palabras clave}

Arquitectura gótica, Cataluña, Valencia, semántica de la arquitectura, oficios artísticos.

\begin{abstract}
This paper analyses architecture semantics at the end of the Middle Ages, starting mainly with Catalonian and Valencian examples. First of all, we examine terms such as mestre d'obres, mestre de cases, and imaginaire, which are often used as synonyms. On the other hand, the study of many other less common ones, such as architect and builder, can help us to clarify a rather complex building reality. The analysis of the documents allows us to strengthen our understanding of the versatility of the medieval master builders, the prestige that some of them acquired, and the relationships that they established with other related professions.
\end{abstract}

\section{Keywords}

Ghotic architecture, Catalonia, Valencia, semantics of architecture, artistic crafts.

\section{Resum}

Aquest article vol analitzar la semàntica de l'arquitectura de finals de l'Edat Mitjana, partint d'exemples catalans i valencians. En primer lloc, se sotmetran a estudi termes que són emprats com a sinònims, com és el cas del mestre d'obres, mestre de cases i imaginaire. En segon lloc, altres menys habituals

1 Dpto. de Historia del Arte. Universidad de Valladolid. Correo electrónico: vdlorente@gmail.com. ORCID: https://orcid.org/0000-0003-4605-9190. 
com arquitecte i aparellador. L'anàlisi de la documentació permet aprofundir en la versatilitat dels constructors medievals, comprende el prestigi que van assolir determinats mestres i les relacions que es van establir amb altres oficis.

\section{Paraules clau}

Arquitectura gòtica, Catalunya, València, semàntica de l'arquitectura, oficis artístics.

\section{Introducción}

La terminología con la que los documentos se refieren a los artífices de la piedra en las postrimerías de la Edad Media es uno de los problemas que surgen al estudiar la arquitectura gótica². Oficios como arquitectos, aparejadores, ingenieros, canteros, albañiles y escultores, presentan en la actualidad unas fronteras claramente definidas. La documentación medieval, sin embargo, no siempre hace distinciones entre estos oficios, que en muchas ocasiones iban de la mano, pero exigían unas destrezas diferentes. Es habitual que se califique a los individuos en función de las labores que realizaban dentro de la obra, o de su categoría: maestros, oficiales, aprendices, mozos y esclavos. La documentación notarial constituye una fuente bastante fiable para conocer el oficio de los diferentes profesionales, mientras que otros documentos, como los libros de obra de las fábricas edilicias, no suelen tener tanta consideración en estos aspectos. Partiendo de todas estas premisas, realizar un análisis de esta terminología presenta un gran interés, más allá del ámbito filológico, ya que nos acerca a la concepción que la sociedad bajomedieval tenía de los trabajadores de la piedra.

\section{El problema de la variedad terminológica}

Los documentos de la Corona de Aragón se refieren a los profesionales de la construcción con una terminología muy variada. Algunos de los más habituales son mestre d'obra, mestre de cases, imaginaire, piquer, pedrapiquer, pedrer, mestre d'argamassa, obrer de vila, o mestre de paredar. En ocasiones, estos profesionales de la piedra también se califican con vocablos que aluden al trabajo de la madera, como fuster, maçonero e incluso, de forma excepcional, mestre d'aixa ${ }^{3}$. Calificativos como architector o apara-

\footnotetext{
2 Artículo realizado en el marco del proyecto PGC2018-093822-B-I00: “Corte y Cortes en el tardogótico hispano. Narrativa, memoria y sinergias en el lenguaje visual", concedido por el Ministerio de Ciencia, Innovación y Universidades. Este trabajo forma parte de una Tesis Doctoral dirigida por las profesoras Matilde Miquel Juan y Olga Pérez Monzón, defendida en abril de 2018 en la Universidad Complutense de Madrid. Agradezco a los dos revisores del artículo sus observaciones y sugerencias, que han servido para mejorar el texto y el aparato crítico.

3 El mestre d'aixa era un carpintero que proyectaba y construía embarcaciones. Sobre el trabajo de los carpinteros en los oficios de la construcción véase: Domenge Mesquida y VIDAL Franquet, "Construir i decorar un teginat: del document a l'obra"; IzQUIERDO ARANDA, "Carpintero y maestro constructor en la arquitectura gótica valenciana (siglos XIV-XV)"; - La fusteria a la València medieval (1238- 1520).
} 
llador son mucho menos frecuentes ${ }^{4}$. En este trabajo nos vamos a centrar en el maestro de obras, el maestro de casas, el arquitecto, el aparejador y el imaginero. Con estos vocablos se califican a los máximos responsables de los aspectos constructivos, y en consecuencia, fueron ellos, junto con los promotores de las obras, quienes tuvieron un mayor grado de participación en el diseño y la creación arquitectónica.

En apariencia, los documentos medievales no parecen prestar mucha atención a la semántica de la construcción, y de hecho es frecuente que un mismo artífice aparezca referido de diferentes formas, a veces incluso en la documentación de la misma fábrica ${ }^{5}$. Por ejemplo, en los libros de obra de la catedral de Valencia podemos encontrar al maestro mayor Martí Lobet (1417-1439) nombrado como piquer, mestre de l'obra, mestre de la maçoneria, maçoner, mestre de fulles, mestre d'obra de talla, e imaginaire. Otro tanto ocurre con su sucesor en el cargo, Antoni Dalmau (1441-1453), calificado como imaginaire, maçoner imaginaire, mestre de la Seu, piquer, pedrapiquer, y magister in arte lapicidea. Estos calificativos nos indican el carácter polifacético de los artífices medievales, pero también nos obligan a mostrar precaución a la hora de categorizar sus diferentes destrezas y funciones, puesto que en algunos casos es difícil establecer sus aptitudes y habilidades, y la documentación no siempre ayuda a clarificarlo.

\subsection{La jerarquía del taller: el mestre d'obra}

Los grandes obradores de cantería estaban organizados en torno a una jerarquía muy rígida. A la cabeza del taller se encontraba el maestro, un cantero que había alcanzado esta categoría profesional tras haber superado un examen bajo la atenta mirada de la cofradía de canteros de la ciudad, y por tanto, tenía una formación consolidada basada en el conocimiento empírico, y traducida en la capacidad para solucionar los diferentes problemas técnicos que se podían presentar. Bajo sus órdenes se encontraban una gran cantidad de artesanos especializados en todo tipo de tareas, y que trabajaban de forma asalariada o por destajo. Por debajo de todos ellos estaban los aprendices, personas jóvenes que vivían con el maestro durante el tiempo que duraba su formación. En último lugar se hallaban los esclavos, que podían realizar cualquier tipo de tarea no cualificada.

El término mestre d'obra es quizás el que más podría acercarse a la concepción que se tiene en la actualidad de un arquitecto. Era éste quien asumía todas las labores relacionadas con la construcción, desde realizar los diseños de los proyectos y las trazas, hasta las labores de cantería y albañilería, además de dirigir la construcción, gestionar

\footnotetext{
Alonso Ruiz, "Los talleres de las catedrales góticas y los canteros del norte"; Fité Llevot, "Los profesionales de la construcción en época medieval (siglos XIV-XV)".

5 Español BertrÁn, "La transmisión del conocimiento artístico en la Corona de Aragón (siglos XIV-XV)", pp. 97-103; Domenge Mesquida y Vidal Franquet, “"A coneixença de mestres experts». Les visures de l'obra gòtica a través de la documentació catalana”, pp. 23-28; JUAN VICENS, Lapiscida vel ymaginarius, pp. 40-44.
} 
los recursos y ocuparse de administrar la fábrica ${ }^{6}$. Para ello necesitaba dominar el dibujo, la geometría, y tener unos conocimientos básicos de matemáticas. Con frecuencia, también estaba capacitado para realizar tareas escultóricas.

El grado de maestría era un requisito para ocupar el cargo de mestre major de una catedral, si bien solo unos pocos privilegiados llegaron a alcanzar tan alta responsabilidad. El maestro mayor era el encargado de la dirección de la fábrica y de coordinar las labores de todos los artesanos. Este puesto podía ser ocupado por un maestro cantero o un maestro carpintero, e incluso otros profesionales artísticos, en función de las necesidades del cabildo. En algunos lugares se dio una dualidad del cargo, como en Mallorca o Valencia, en donde se llegó a contar a la vez con un maestro mayor picapedrero y otro carpintero ${ }^{7}$. En la mayoría de los casos la dirección de las obras catedralicias recayó en artífices vinculados a la misma ciudad, con un reconocimiento profesional conocido por los clientes. El hecho de que los extranjeros careciesen de estas referencias sin duda dificultó su acceso a la dirección de las grandes fabricas catedralicias, pero tenemos ejemplos que demuestran que esto no siempre fue un obstáculo insalvable. El normando Charles Gautier, que ya contaba con una sólida trayectoria desarrollada en Barcelona y Lleida, dirigió la construcción de la catedral de Sevilla durante buena parte de sus primeros años, y el catalán Antoni Dalmau, ampliamente documentado en diferentes trabajos en la ciudad de Valencia, también fue propuesto por el cabildo para ocupar este cargo en la misma fábrica ${ }^{8}$ No eran muchos los que llegaban a dirigir la construcción de una catedral, pero los que lo conseguían tenían garantizado el prestigio, la manutención, y unos ingresos estables, pues con frecuencia contaban con una retribución fija, tanto si se encontraban a pie de obra como si se estaban trabajando en otro lugar. Además de tomar el mando en la

\footnotetext{
6 La bibliografía sobre los maestros de obras, sus funciones y su consideración social es muy amplia. Citamos a continuación algunos estudios de referencia en el ámbito de la península Ibérica: YARZA LUACES, "Artista-artesano en el gótico catalán, I"; Rubio SAMPER, "La figura del arquitecto en el período gótico"; YArza Luaces, "El artista gótico hispano"; - "Artistes-artisans de la Couronne de Castille au temps des Rois Catholiques"; Galarza TorTajada, "El maestro de obras en la Edad Media"; YARza Luaces "Artistaartesano en la Edad Media hispana"; VICTOR, La construcció i els seus oficis a la Girona del segle XV; Fité "Los profesionales de la construcción en época medieval (siglos XIV-XV)"; MARTíneZ DE AGUiRre, "Investigaciones sobre arquitectos y talleres de construcción en la España medieval cristiana"; VICTOR, "La mà d'obra"; Alonso Ruiz, "El maestro de obras catedralicio en Castilla a finales del siglo XV".

7 Para Mallorca: Domenge Mesquida, L'obra de la Seu, pp. 199-205; Cerdè Garriga, "Los Salort (14291523)", p. 454. Para Valencia: MiQuel JuAn, "Martí Lobet en la catedral de Valencia (1417- 1439)"; IzQUIERDO ARANDA, "Carpintero y maestro constructor en la arquitectura gótica valenciana (siglos XIV-XV)"; - La fusteria a la València medieval (1238- 1520); - "Veedors, marquejadors, maestros". En el ámbito castellano, la investigación realizada por la profesora Palomo en la catedral de Cuenca revela una situación bastante similar: PALOMO, La catedral de Cuenca en el contexto de las grandes canterías catedralicias castellanas en la Baja Edad Media, t. 2, pp. 61-65.

8 Charles Gautier es conocido también como el maestro Carlí o Carlín. Para su maestría en Sevilla: Jiménez Martín, "Los primeros años de la catedral de Sevilla: nombres, fechas y dibujos". Para Antoni Dalmau: GómeZ-Ferrer LozAno, "La cantería valenciana en la primera mitad del siglo XV", pp. 101-102; - "El maestro de la catedral de Valencia Antoni Dalmau (act. 1435-1453)"; López LoRenTe, La transmisión del saber técnico de los arquitectos en la Corona de Aragón en el tardogótico, pp. 191-208.
} 
dirección de las fábricas catedralicias, algunos maestros, como Arnau Bargués (13981406) en Barcelona o Pere Balaguer (1408-1424) en Valencia, materializaron muchos de los proyectos urbanísticos y arquitectónicos que dictaban los representantes de las ciudades, y trabajaron también al servicio de la Corona, y de numerosos clientes privados, pertenecientes en su mayoría a la nobleza y la burguesía9 .

Otra denominación que con frecuencia se asocia a los profesionales de la construcción es la de mestres de cases. Parece que éstos tenían unas capacidades más limitadas que los mestres d'obres, aunque en realidad resulta difícil establecer la frontera entre las competencias que podían tener asignadas cada uno. Algunos autores indican que los maestros de casas no tenían capacidades para realizar obras de escultura arquitectónica, ni de resolver cuestiones técnicas complejas, quedando su trabajo circunscrito, en la mayoría de las ocasiones, a obras menores, de carácter civil, pudiendo equipararse con la figura de los albañiles ${ }^{10}$. En la mayoría de los casos, efectivamente, sus aptitudes artísticas parecen bastante acotadas, pero de nuevo encontramos llamativas excepciones, que demuestran lo ambigua que resulta la documentación en estos aspectos. En un documento de la catedral de Barcelona fechado en 1431 se califica como mestre de cases al reputado Pere de Santjoan, cuyas nociones de escultura quedan demostradas en el portal del Mirador en Palma de Mallorca ${ }^{11}$. Cuando los encontramos documentados dentro de las obras catedralicias, no es ni mucho menos habitual que la dirección de la fábrica recayese en un maestro de casas, pues por lo general, éstos se limitaban a ocupar los cargos de meros oficiales. Pero también son varios los que se ocuparon de la dirección de las obras, y de la materialización de edificios de gran envergadura. Un ejemplo lo encontramos en la catedral de Barcelona, cuya maestría mayor entre (ca.) 1358 y 1388 recayó en el maestro de casas Bernat Roca ${ }^{12}$. En la misma obra, entre 1398 y 1406, encontramos también al ya citado Arnau Bargués. Este último desarrolló destrezas que fueron ampliamente reconocidas por los clientes, pues también trabajó al servicio de Martín el Humano, dirigiendo la fábrica del monasterio de Poblet (ca. 1397-1407), y para el municipio de Barcelona (13991413), en donde realizó, entre otras, la fachada del Ayuntamiento (1399-ca. 1402)13. Además, fue uno de los que acudió a la primera junta de arquitectos de la catedral

\footnotetext{
9 Un resumen de la actividad de Arnau Bargúes en: Terés, "Arnau Bargués i els seus escultors"; - "Arnau Bargués (c. 1374-1413)". Sobre la trayectoria profesional de Pere Balaguer puede verse: SERRA DesfiLis y Miquel Juan, "Pere Balaguer y la arquitectura valenciana entre los siglos XIV y XV".

10 Almuni Balada, La catedral de Tortosa als segles del gòtic, vol. I, pp. 555-560; Fité Llevot "Los profesionales de la construcción en época medieval (siglos XIV-XV)", p. 36.

11 Durliat, "Un artiste picard en Catalogne et à Majorque: Pierre de Saint-Jean", p. 119. Sobre este maestro véase: Freixas CAmps L'Art gòtic a Girona (segles XIV i XV); Terés Tomìs, "Pere de Sant-Joan, i el Mestre de la cadira episcopal de Barcelona. Hipòtesi sobre una identitat"; Palou SAMPOL, "Pere de Santjoan"; Valero Molina, "L'etapa gironina de l'escultor Pere de Santjoan".

12 Sobre Bernat Roca véase: Ortoll Martín, "Bernat Roca, un artífex pluridisciplinar"; Terés TomÀs, "Les obres de la catedral de Barcelona i la intervenció de Francesc Marata".

13 Verrié, "Un arquitecto en la Barcelona medieval", vol. IV, pp. 146-152; Duran SanPere, Barcelona $i$ la seva historia; TERÉs TomÀs, "Arnau Bargués, arquitecto de la ciudad de Barcelona"; - "Arnau Bargués i els seus escultors"; - "Arnau Bargués (c. 1374-1413)".
} 
de Girona (1386), para discutir la continuidad de la fábrica con una nave única, junto con Bartomeu Sisbert, otro "magister domorum civitatis Barchinone"14. La llamada de ambos a una reunión de estas características demuestra el valor que se daba a su saber técnico. En Valencia encontramos el caso de Joan del Poyo (doc. 1402-1439), un personaje destacado en la historia del urbanismo de la ciudad del Turia, y que demostró amplios conocimientos de arquitectura, carpintería e ingeniería, como ha estudiado el profesor Serra ${ }^{15}$.

Una consecuencia de la versatilidad que demostraron estos artífices de la piedra fue la interferencia con otros oficios que resultaban cercanos, como los carpinteros, cuya colaboración en las obras era imprescindible para fabricar grúas, cimbras y andamia$\mathrm{jes}^{16}$. Algunos maestros de casas incluso se formaron con profesionales de la madera, como Bernat Gual, que fue acogido como aprendiz por el mestre d'aixa Domingo Ferrer $^{17}$. Nos han llegado algunas noticias que evidencian una competencia desleal entre los maestros de casas y los fusteros, y que debieron generar todo tipo de dificultades. En Barcelona, por ejemplo, el Consell de Cent tuvo que promulgar en 1470 las ordenanzas "de fusters e mestres de cases", limitando las tareas que estos últimos podían realizar con madera y las que se encontraban circunscritas a los carpinteros ${ }^{18}$. El problema no debió solucionarse, dado que en 1477 se volvió a insistir, limitando todavía más los trabajos que se autorizaban a cada menestralía ${ }^{19}$. También en Valencia encontramos ejemplos que evidencian interferencias similares. La documentación de la Sotsobreria de Murs $i$ Valls muestra en 1449 al albañil Jaume Gallent entregando sierras y madera para confeccionar ventanas ${ }^{20}$. En realidad en todos los territorios de la Corona de Aragón la situación debió ser parecida. Quizás esto sea el motivo por el que las dos cofradías de los oficios de la construcción en Zaragoza, que representaban tanto a los cristianos (1397) como a los musulmanes (1503), acogieron en su seno a los albañiles, carpinteros y fabricantes de cubas ${ }^{21}$. También por una razón similar se

\footnotetext{
14 Las actas de esta primera reunión fueron publicadas por primera vez en: SERRA RÀFols, "La nau de la seu de Girona". El documento se encuentra traducido al castellano en YARZA LuACES, Arte Medieval II: Románico y Gótico, pp. 308-315. Sobre esta reunión véase el reciente estudio de Domenge MesquidA y Sureda Jubany, "Una o tres naus? Les consultes de 1386 i 1416 sobre la continuació de la catedral de Girona". Para los maestros de Barcelona que participaron en la primera reunión: Bernaus, "«Mestres de Barcelona, experts en art»: la participación de maestros de Barcelona en la consulta de la catedral de Gerona (1386)".

15 Serra Desfilis, "Al servicio de la ciudad".

16 Gómez-Ferrer Lozano y Zaragozá Catalán, Pere Compte, arquitecto, pp. 200-212; SÁnchez Verduch, "Maestros de obras en la Valencia gótica: personajes polifacéticos".

17 Sobre este maestro véase: Vidal Franguet, "L'activitat quotidiana d'un mestre de cases medieval", pp. 917-923; - "Bernat Gual, mestre de cases de la ciutat de Tortosa".

18 Bonnassie, La organización del trabajo en Barcelona a fines del siglo XV, pp. 59-60; Madurell MARIMON, "Les ordinacions de l'ofici de mestre de cases de Barcelona", p. 234.

19 Bernaus, "Capítols, privilegis i ordinacions dels mestres de cases al final de l'edat mitjana", pp. 73-74.

20 IzQuierdo ARANDA, "Carpintero y maestro constructor en la arquitectura gótica valenciana (siglos XIV-XV)", p. 218.

21 IbÁÑEz FernÁNDEZ, "Le corporazioni della costruzione nella Zaragoza del cinquecento"; LóPEz LoRENTE, La transmisión del saber técnico de los arquitectos en la Corona de Aragón en el tardogótico, pp. 30-47.
} 
pudo incluir en la cofradía de Girona (1419) a los canteros, carpinteros, ballesteros, y desde 1482, a los maestros de casas ${ }^{22}$.

De la misma forma que estas situaciones debieron ser frecuentes, también fue imprescindible la colaboración entre maestros de ambos oficios. Un ejemplo cercano lo encontramos en el viaje que emprendió desde Barcelona en 1418 el maestro Bartomeu Gual junto al carpintero Joan Ayigues para estudiar el cimborrio de la catedral de Valencia cuando se le encargó el diseño para esta estructura en la seo de la ciudad Condal ${ }^{23}$. La compañía de este fuster puede justificarse para estudiar el andamiaje, pero no debe descartarse que Ayigues también se encontrase relacionado con el diseño arquitectónico, y que su cometido fuese elaborar una maqueta de la estructura ${ }^{24}$. Tenemos varios ejemplos documentados que evidencian la existencia de este tipo de maquetas arquitectónicas. Parece probable que una de las que se han conservado sea la estructura custodiada en el Museo Municipal de Valencia y atribuida a Antoni Dalmau, que podría corresponderse con un diseño para el remate de la torre campanario de la Catedral ${ }^{25}$ (Figura 1). En el mismo sentido cabe recordar también el viaje que financió a Sicilia Alfonso el Magnánimo al carpintero Joan Benet para que le llevase un modelo en madera con "les mostres de les quatre torres" del Real de Valencia, y que probablemente fuese un encargo expreso del rey para visualizar las obras que estaba financiando a través de una maqueta construida por el propio fustero ${ }^{26}$.

22 Chamorro Trenado, "La cofradía de los Cuatro Santos Mártires en el siglo XV".

23 Carreras Candi, "Les obres de la catedral de Barcelona", p. 313; Bracons y Terés, "La catedral de Barcelona”, p. 313; Miquel Juan, "Martí Lobet en la catedral de Valencia (1417- 1439)”, p. 106.

24 Montero Tortajada, La transmisión del conocimiento en los oficios artísticos, pp. 100-101.

25 IbáÑez Fernández (coord. y ed.), Trazas, muestras y modelos de tradición gótica en la Península Ibérica entre los siglos XIII y XVI, pp. 120-122; LÓPEZ LORENTE, La transmisión del saber técnico de los arquitectos en la Corona de Aragón en el tardogótico, pp. 113-115.

26 SAnchis Sivera, "La escultura valenciana en la Edad Media: notas para su historia", pp. 21-22; GómezFerrer Lozano, El Real de Valencia (1238-1810). Historia arquitectónica de un palacio desaparecido, p. 79 . 
Figura 1: Valencia: Maqueta de una aguja gótica. ca. 1441-1453.

\section{Madera de pino, tela y hierro}

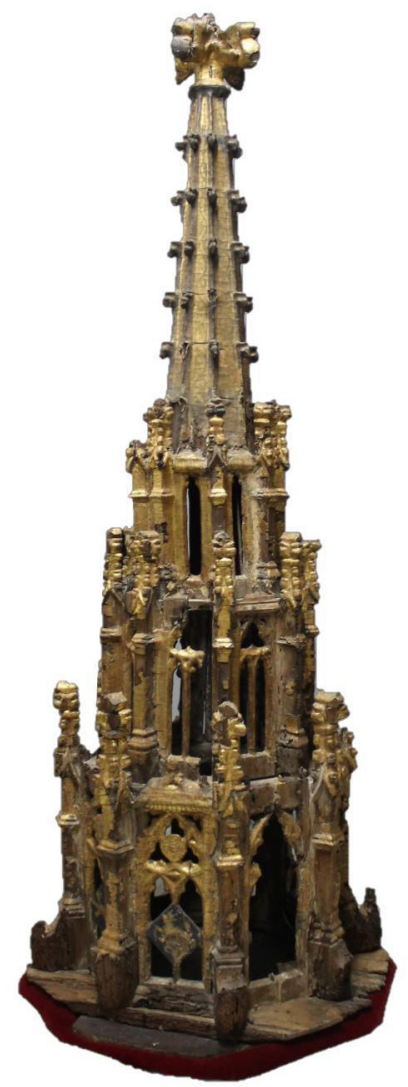

2.2. Arquitectos, aparejadores e imagineros

El término architector es mucho menos frecuente en esta época que el de maestro de obras, aunque aparece de forma excepcional en la documentación ${ }^{27}$. Lo hemos encontrado mencionado en relación a dos de los maestros mayores de la catedral de Tortosa de forma sucesiva: Antoni Taix (1489), un maestro de casas, al que se le califica como un "architecto civis Dertuse"28; y su sucesor, Antoni Queralt (1495-1498), que también se describe como "architector, habitator Dertuse" en un documento de 149129. Fuera del

\footnotetext{
27 Un estudio sobre la evolución del término 'arquitecto' en PEvsner, “The Term 'Architect' in the Middle Ages". Sobre el uso de este vocablo en los territorios de la Corona de Aragón puede verse RuBIo SAMPER, "La figura del arquitecto en el período gótico", pp. 102-105; Company, L'art i els artistes al País Valencià Modern (1450-1600), pp. 157-158; JuAN VICENS, Lapiscida vel ymaginarius, pp. 34-35.

28 Almuni Balada, La catedral de Tortosa als segles del gòtic, vol. I, pp. 491 y 556.

29 Vidal Franquet, “Una obra D’ Antoni Queralt a cavall de Lleida y Tortosa”, p. 127.
} 
ámbito de las catedrales, también aparece alguna mención de este vocablo. La profesora Antònia Juan Vicens lo ha localizado en el nombramiento de Guillem Sagrera como maestro mayor del palacio de la Almudaina de Palma de Mallorca (1454), en donde se indica que su antecesor, Antoni Boschà, era un "architectum et lapiscidam" 30 . Antoni Boschà fue maestro mayor del rey en este palacio hasta su muerte en 1453, y se le califica en otro documento como mestre picapedres ${ }^{31}$. La misma autora señala de nuevo la aparición de este término unos años más tarde, en 1503, en relación con una junta de expertos que se reunió para discutir la mejor manera de acometer la construcción del ábside de la iglesia del monasterio de Santa Clara, y en donde los maestros Andrea Salort, Pere Sastre y Joan Salort son calificados como architectoribus, mientras que Joan Sagrera, Jeroni Ferrer, Daniel Pou y Joan dez Payti como lapiscidae ${ }^{32}$.

Resulta difícil esclarecer el significado del término arquitecto. Todos los documentos en los que lo hemos encontrado son de unas fechas bastante tardías, y su uso se irá haciendo más frecuente conforme avancen las nuevas formas del Quinientos. Ximo Company indica que, en el ámbito catalán, las pocas veces que aparece este vocablo es utilizado como un sinónimo de mestre de cases $^{33}$. En el contexto ultrapirenaico Pevsner señala que en ocasiones excepcionales se utilizaba para denominar a los carpinteros, señalando como ejemplo el del fustero Roger Noblet, al que en 1514 se le cita como arquitecto en la catedral de Rouen ${ }^{34}$. Esto es lo que parece ocurrir en la documentación de la junta de expertos del convento mallorquín de Santa Clara, en donde Andrea Salort, Pere Sastre y Joan Salort reciben este calificativo, a pesar de ser reconocidos profesionales en el trabajo de la carpintería ${ }^{35}$. En cualquier caso, su utilización es muy escasa, y aunque los datos que tenemos son pocos, en ninguno parece que su uso se refiera a un trabajo diferente al de un maestro de obras.

El vocablo aparellador es todavía más inusual que el de architector. Sandrine Victor indica que el aparaylador o peradador sería aquel que levantaba los muros y dominaba el uso de la escuadra y la plomada ${ }^{36}$, mientras que Jiménez Martín lo define como el "cantero que ejercía el papel de subdirector de la obra interpretando y difundiendo las instrucciones del maestro mayor, y sustituyéndolo en caso de necesidad" ${ }^{37}$. Sus funciones no parecen alejarse demasiado de las que fueron descritas unos años más tarde por Fray José de Sigüenza, en su manuscrito sobre la construcción del monasterio de El Escorial:

\footnotetext{
30 Muntaner Bujosa, "Piedra de Mallorca en el Castelnuovo de Nápoles", p. 629, cit. en JuAn Vicens, Lapiscida vel ymaginarius, p. 34.

31 Muntaner Bujosa, "Partidas de gasto curiosas", p. 365; Juan Vicens, "El estatus social del artesano de la piedra a finales de la Edad Media”, p. 245, n. 10.

32 Llompart, Miscelánea documental de pintura y picapedrería mallorquina, pp. 85-86, doc. 162, cit. en JuAn VICENS, Lapiscida vel ymaginarius, p. 35.

33 Company, L'art i els artistes al País Valencià Modern (1450-1600), p. 157.

34 Pevsner, "The Term 'Architect' in the Middle Ages", p. 557.

35 Sobre la familia de los Salort, véase CERdì GARrigA, "Los Salort (1429-1523)".

36 VICTOR, "La mà d'obra", p. 208.

37 Jiménez Martín, Palabras de piedra, p. 31.
} 
"Aparejador se llama al que, después de que el arquitecto ha dispuesto toda la fábrica, apareja la materia, hace los cortes y divide las piezas para que labren bien, con igualdad y hermosura en toda la fábrica, y por él se trazan los modelos particulares por donde se gobiernan los destajeros, que en lengua latina se llaman redemptores" 38 .

En la documentación francesa y alemana con frecuencia aparece la figura del parlier o parler que, literalmente sería aquel que hablaba, el que interpretaba las trazas del arquitecto y transmitía los conocimientos al equipo de canteros ${ }^{39}$. El término podría derivar del latín appar (il) ator, que el francés adoptó como appareilleur, el catalán aparellador y el castellano, aparejador. Se trata de un profesional que, quizás a lo largo del siglo XIII, debió desvincularse de la figura del maestro de obras ${ }^{40}$.

Del análisis de la documentación de la Corona de Aragón se deduce que los aparejadores eran un mando intermedio entre el maestro mayor, encargado de realizar las trazas y elegir los materiales, y los equipos de pedrapiquers. Con frecuencia, los maestros de obras más afamados debían atender muchos encargos de forma simultánea, y no siempre podían permanecer a diario en la fábrica, por lo que necesitaban delegar en personas de su confianza para resolver las cuestiones cotidianas. En el momento en que se difundió el dibujo técnico dejó de ser necesario que el arquitecto permaneciese de forma continuada mientras se materializaba la construcción. El maestro mayor sería el encargado de elegir los materiales, permanecer en la obra los primeros días para organizar el trabajo, y realizar visitas periódicas con el objetivo de supervisar su desarrollo; mientras que los aparejadores permanecerían a pie de obra, resolviendo los problemas que podían surgir en las labores diarias, proveyendo a la obra de materiales cotidianos como cuerdas o escaleras, interpretando los diseños que había dado el maestro, y realizando los moldes y plantillas que permitirían trabajar a los canteros y entalladores. En ocasiones era el maestro mayor el mismo que realizaba las funciones de aparejador, pero en otras, este cargo recaía en un artífice distinto.

El hecho de que el empleo de este término sea tan escaso en la documentación puede deberse a que no todos los arquitectos contasen con un aparejador, y a que su función se confundiera con la del maestro de obras.

En la Corona de Aragón solo hemos encontrado este vocablo en dos ocasiones, en unas fechas tempranas, y siempre en el ámbito catalán. Aparece por primera vez en un documento en el que Pere Moragues se comprometía a dirigir la fábrica de la catedral de Tortosa en 1382, y en donde se contrata de forma vitalicia a Joan de Frenoy

\footnotetext{
38 SigüEnZA, Fundación del Monasterio de El Escorial, p. 23.

39 Por ejemplo, en la reunión que se celebró en Ratisbona en 1459 para que los diferentes profesionales vinculados a los oficios de la construcción unificasen sus estatutos, se expresaron de la siguiente manera: "Aussi nul ouvrier, nul maître, nul parlier, nul journalier, n'enseignera à quincone n'est pas de notre métier et n'a jamais fait travail de maçon, comment tirer l'elevation du plan". ReCHT, Les bâtisseurs des cathédrales, p.123.

40 Recht, "Les termes techniques de l'architecture médiévale", p. 84.
} 
(1382-1402/1410), al que se le califica como su aparallador ${ }^{41}$. Volvemos a encontrar un apparallador de la obra, esta vez en la catedral de Barcelona durante la maestría de Arnau Bargués (1398-1408), en relación con el piquer Jaume Solà, que es calificado así en un documento de $1402^{42}$.

En Castilla también se ha localizado este término en unas fechas un poco más avanzadas, aunque tampoco es demasiado habitual, y no podemos afirmar que conlleve unas funciones similares. La desaparecida lápida sepulcral que vieron Ponz y Llaguno en la capilla Saldaña del convento de Santa Clara de Tordesillas decía: “Aquí yace Maestre Guillem de Roan / maestro de la iglesia de León, et apareia/dor de esta capilla que Dios perdone; / et finó a VII de deciembre año de mil et / CCCC et XXX et un años"43. El término lo encontramos de nuevo en los libros de obra de la catedral de Sevilla, donde se califica en 1448 a Pedro de Toledo como aparejador de la obra del maestro Carlín ${ }^{44}$. A pesar de que es poco frecuente encontrar este vocablo en los documentos, el trabajo de los aparejadores es conocido en importantes empresas edilicias de la Corona de Aragón. Por lo general, para referirse a estos trabajadores se emplea el término "mestre", que hace referencia al grado profesional que ostentaban ${ }^{45}$. El profesor Ibáñez ha estudiado esta forma de trabajo en relación al equipo formado por los maestros Isambart y Pere Jalopa en tierras aragonesas. El primero firmó las capitulaciones para construir la capilla de San Agustín en la catedral de Zaragoza (1417-1420), y se ocupó de proporcionar el diseño, visitar las canteras para elegir el tipo de piedra y el camino más adecuado para transportarla, y supervisar la obra desde la distancia. A cargo de la obra se quedaría el maestre piedrapiquero Pere Jalopa, dirigiendo a las cuadrillas de canteros, mientras de forma simultánea, Isambart acometía la construcción de la capilla de los Corporales en Daroca ${ }^{46}$. En la catedral de Tortosa, Jacobo Vidal ha propuesto una solución similar con respecto al architector Antoni Queralt, que realizaría el trabajo de aparejador de Pere Compte durante su maestría,

\footnotetext{
${ }^{41}$ Almuni Balada, La catedral de Tortosa als segles del gòtic, vol. II, pp. 761-762, doc. 65. Sobre Joan de Frenoy véase: Vidal Franquet, "Sobre la personalitat i l'activitat de Joan de Frenoy. Apunts". De esta forma, se debe adelantar unos años la aparición del término en el ámbito hispano, pues con frecuencia se ha afirmado que esta profesión apareció en nuestro territorio en el siglo XV: FALCón MárQueZ, El aparejador en la Historia de la arquitectura, p. 15.

42 Coromines, Diccionari etimològic i complementari de la llengua catalana, vol. VI, p. 255; Terés TомÀs, "Obres del segle XV a la Catedral de Barcelona"; - "Les obres de la catedral de Barcelona i la intervenció de Francesc Marata".

43 Ponz, Viaje de España, vol. XII, p. 143; Llaguno y Amirola, Noticia de los arquitectos y arquitectura de España desde su restauración, vol. I, pp. 37-38 y 102-103. Rada y Delgado también afirma haberla visto, aunque en su transcripción la fecha de su muerte se retrasa hasta el 8 de diciembre de 1433: RADA y Delgado, Viaje de SS. MM. y AA, por Castilla, León, Asturias y Galicia en el verano de 1858, p. 163. Sobre esta capilla: Alonso Ruiz, "Las trazas de montea en la construcción gótica".

44 Jiménez Martín, "Las fechas de las formas", p. 65 y 71.

45 Mortet, "La maîtrisse d'oeuvre dans les grandes constructions du XIII siècle et la profession d'appareilleur", p. 265.

46 IbÁÑez Fernández, "Con el correr del sol"; - La capilla del palacio arzobispal de Zaragoza en el contexto de la renovación del Gótico final en la Península Ibérica; - "The Northern Roots of Late Gothic Renovation in the Iberian Peninsula”.
} 
quedando este último comprometido a trasladarse a la ciudad tan sólo tres veces al año $^{47}$. En Lleida, durante todo el tiempo que Carlín estuvo al frente de la dirección de la Seu Vella (1410-1427), el año que más días trabajó fue 1410, cuando permaneció en la fábrica noventa y dos jornadas; mientras que en 1413 sólo trabajó dos, en 1424 cinco, y en 1411, 1416, 1417, 1422 y 1423 no estuvo ningún día ${ }^{48}$. Por tanto, hemos de asumir que durante largos periodos de tiempo fueron sus ayudantes los que se hicieron cargo del avance de las obras durante la ausencia del maestro, al margen de los días festivos, o aquellos en los que no se podía trabajar por alguna circunstancia extraordinaria como podía ser la falta de materiales ${ }^{49}$.

Los aparejadores, aunque no gozaban del sueldo ni la consideración de los maestros mayores, por lo general eran canteros de primer orden y con una gran capacidad técnica, aunque no siempre la historiografía los ha tenido en consideración, en parte debido a que los datos que tenemos son menos numerosos, y con frecuencia no siempre tan precisos como sería deseable.

Por último, debemos hacer referencia al vocablo imaginaire. Este término, con todas sus variantes idiomáticas, ha sido discutido por la historiografía, pues no son pocas las ocasiones en las que la documentación se refiere a estos profesionales como maestros de obra e imagineros. Este calificativo no solo aparece en relación con artífices de la piedra, también lo encontramos en el ámbito de la pintura. La profesora Miquel, que se ha acercado a su estudio desde esta perspectiva, define a los imagineros como "aquellos artistas que sabían crear y dibujar en el plano la realidad tridimensional, con sus luces y sombras, en composiciones ajustadas y completas, que mostraban el dolor humano o la felicidad de la santidad" "50. En relación con los oficios de la construcción, el vocablo podría hacer referencia a un artífice capacitado para realizar trabajos de escultura arquitectónica con gran maestría. Los ejemplos que coinciden con esta doble habilidad son innumerables: Pere Morey en la catedral de Palma de Mallorca (1369-1394) ${ }^{51}$, Guillem Morey en la de Girona (1375-1397) $)^{52}$, Antoni Canet en Barcelona (1394-1426) ${ }^{53}$, Joan

\footnotetext{
47 Vidal Franquet, "Pere Compte, mestre major de l'obra de la Seu de Tortosa", p. 417.

48 Argiles Aluja, "Maestro Carlín en Cataluña", p. 67. No se conocen los lugares en los que trabajó durante estos años, a la vez que dirigía las obras de la catedral de Lleida.

49 El profesor Martínez de Aguirre ha analizado el calendario laboral de los constructores en Navarra, concluyendo que estaban exentos de trabajar todos los domingos del año, a los que habría que sumar un número de fiestas variable, entre 25 y 50: Martínez de Aguirre, "Calendario laboral, fiestas y primeras huelgas de constructores en la Navarra medieval (1346-1448)".

50 Miquel Juan, "Dibujo y diseño", p. 33.

51 Domenge Mesquida, L'obra de la Seu, pp. 205- 220; Palou Sampol, "Pere Morey, mestre major del portal del Mirador de la catedral de Mallorca"; Domenge Mesquida, "Le portail du Mirador de la Cathédrale de Majorque: du document au monument"; JuAn Vicens, Lapiscida vel ymaginarius, pp. 168-174.

52 Domenge Mesquida, "Guillem Morey a la seu de Girona (1375-1397). Seguiment documental". - "Guillem Morei i l'activitat gironina".

53 Terés TomÀs, "Antoni Canet, un artista itinerant a la catedral de Barcelona"; - "Antoni Canet, arquitecte i escultor".
} 
Lobet (1404-1408)54, Marti Lobet (1417-1439) $)^{55}$, o Antoni Dalmau (1441-1453) ${ }^{56}$ en la de Valencia, entre otros muchos ${ }^{57}$. Se trata, en todos los casos, de artífices especializados en trabajos de carácter escultórico y decoración arquitectónica, disciplinas en las que seguramente habían recibido su formación inicial, que también aceptaron emprender obras de carácter edilicio.

En otras ocasiones, aunque en la documentación no se mencione el vocablo, es evidente que los clientes valoraron especialmente la capacidad de diseño escultórico de los grandes arquitectos. Un caso paradigmático es el del maestro Carlín en la catedral de Barcelona. La obra para la que le contrató el cabildo, el diseño de la gran portada de la fachada principal (1408), es básicamente un dibujo de escultura arquitectónica ${ }^{58}$. Su trayectoria posterior en las catedrales de Lleida y Sevilla deja fuera de toda duda que nos encontremos ante un maestro con un dominio extraordinario de la cantería ${ }^{59}$. En palabras de Alfonso Jiménez, este último edificio "bajo la dirección de Carlín [...] pasó de ser un derribo parcial, unas cimentaciones mestizas y algunos basamentos moldurados de El Puerto de Santa María, para convertirse en una monumental fábrica, [...] alcanzando en su época una cuarta parte de la extensión que se habia previsto" ${ }^{6}$. Quizás no fuese una coincidencia el hecho de que Carlín dominase el diseño de la escultura cuando fue contratado para dirigir las obras de la Seu Vella de Lleida, antes de que dirigiese sus pasos a la ciudad del Guadalquivir. Desde el siglo XIV el Cabildo de esta seo buscaba que los maestros mayores tuvieran nociones tanto de construcción como de imaginería. Esto queda demostrado, no sólo en la nómina de arquitectos que ocuparon este cargo, sino también en la documentación relativa al nombramiento de Andreu Pi, un "magistri constructure domorum" que no debía tener la destreza necesaria para esculpir la piedra, por lo que se incluyó una cláusula en su nombramiento que le obligaba a buscar por su

\footnotetext{
54 SAnchis Sivera, "La escultura valenciana en la Edad Media: notas para su historia", p. 20; - "Maestros de obras y lapicidas valencianos en la Edad Media”, pp. 30-34; SErra Desfilis y MiQuel Juan, "Pere Balaguer y la arquitectura valenciana entre los siglos XIV y XV"; MiQuel JuAn, "Entre la formación y la tradición"; - "Martí Lobet en la catedral de Valencia (1417- 1439)".

55 SAnchis Sivera, "La escultura valenciana en la Edad Media: notas para su historia", pp.17-20; - "Maestros de obras y lapicidas valencianos en la Edad Media", p. 40; MiQuel Juan, "Entre la formación y la tradición"; - "Martí Lobet en la catedral de Valencia (1417- 1439)".

56 Gómez-Ferrer LozAno, "La cantería valenciana en la primera mitad del siglo XV"; - "El maestro de la catedral de Valencia Antoni Dalmau (act. 1435-1453)"; LóPEZ LoRENTE, La transmisión del saber técnico de los arquitectos en la Corona de Aragón en el tardogótico, pp. 191-208.

57 Una relación de los principales arquitectos activos en las catedrales construidas en la Corona de Aragón en el siglo XV y la forma en la que los califican los documentos: López Lorente, La transmisión del saber técnico de los arquitectos en la Corona de Aragón en el tardogótico, pp. 285-322.

58 Bassegoda Nonell, "Projecte de la façana principal de la catedral de Barcelona", pp. 172-173; ArGILÉs Aluja, "Maestro Carlín en Cataluña", pp. 61-64; Alonso Ruiz y Jiménez Martín, La traça de la iglesia de Sevilla, p. 108; IBÁÑEz Fernández (coord. y ed.), Trazas, muestras y modelos de tradición gótica en la Península Ibérica entre los siglos XIII y XVI, pp. 110-112 ; VALERo Molina, "El projecte de la portalada major de la catedral de Barcelona".

59 Para la actividad de Carlín en Lleida Argiles Aluja, "Maestro Carlín en Cataluña”. Los datos que se conocen de este maestro en Sevilla en JimÉnez MARTín, "Los primeros años de la catedral de Sevilla".

${ }^{60}$ Alonso Ruiz y Jiménez Martín, La traça de la iglesia de Sevilla, p. 133; VAlero Molina, "El projecte de la portalada major de la catedral de Barcelona".
} 
cuenta a un imaginaire si así se lo requería el cabildo ${ }^{61}$. En el siglo XV la catedral de Lleida ya estaba prácticamente construida, a excepción de la torre campanario, con lo cual el maestro mayor tan sólo tenía que ocuparse de labores de mantenimiento y obras puntuales, muchas de las cuales estaban relacionadas con la decoración del edificio, lo que justificaría la búsqueda de arquitectos con esta habilidad como escultores.

Algo similar ocurrió en la catedral de Valencia, donde es significativo el caso de Antoni Dalmau al que ya nos hemos referido. Cuando se le contrató como maestro mayor (1441-1453), el cabildo buscaba un profesional versátil, que tuviese cualidades para trabajar la escultura en alabastro, para que de esta forma se pudiera finalizar la portada del trascoro iniciada años atrás e inacabada tras una sucesión de diferentes fracasos de los anteriores maestros. Este artífice se había formado en tierras catalanas con un escultor de la talla de Pere Joan, lo que le capacitaba para llevar a cabo la empresa del trascoro con éxito, como finalmente ocurrió ${ }^{62}$. Dalmau, que en este caso sí es calificado como imaginero, a lo largo de su trayectoria demostró ser un cualificado arquitecto y escultor, con una gran versatilidad y cuyas aptitudes supo aplicar también al trabajo de la madera y de la ingeniería hidráulica. La amplia y versátil formación que había recibido fue también lo que le llevó a contratar la fabricación de un retablo de madera para la iglesia de Burjasot en el año 1440, cuya pintura se encargó en un principio a Jacomart, siendo finalizada por Joan Reixat cuando el primero se marchó a Nápoles ${ }^{63}$.

\section{A modo de conclusión}

Las noticias que hemos planteado evidencian una extraordinaria volubilidad de determinados maestros, tras la cual cabe preguntarse si las habilidades que desarrollaron los grandes artífices de la piedra fueron la consecuencia inmediata de su formación, o si surgió a raíz de sus necesidades de subsistencia. Lo cierto es que la respuesta a ambas cuestiones parece ser afirmativa, dado que sin un aprendizaje adecuado nunca podrían haberse llevado a término muchos de los ingenios que los maestros de la construcción desarrollaron pero, del mismo modo, al no encontrarse sistematizado el aprendizaje, la formación hubo de adaptarse a la necesidad de conocimientos que precisaban los artífices en cada lugar. Sólo desde esta versatilidad profesional los constructores pudieron dar respuesta a unas necesidades que no eran homogéneas en todos los territorios. De la capacidad de adaptación de estos artífices dependía, en gran medida, su éxito profesional.

\footnotetext{
${ }^{61}$ Alonso García, Los maestros de la Seu Vella de Lérida y sus colaboradores, pp. 140-141; Fité LLEVOT, "Los profesionales de la construcción en época medieval (siglos XIV-XV)", p. 38.

62 Sobre Antoni Dalmau véase: Gómez-Ferrer Lozano, "La cantería valenciana en la primera mitad del siglo XV"; - "El maestro de la catedral de Valencia Antoni Dalmau (act. 1435-1453)"; JARDI, "La intervenció d'Antoni Dalmau (†1453) a les galeries del claustre de la catedral de Barcelona"; LóPez LoRENTE, La transmisión del saber técnico de los arquitectos en la Corona de Aragón en el tardogótico, pp. 191-208. 63 SAnchis Sivera, "Maestros de obras y lapicidas valencianos en la Edad Media", p. 44; GómEz-FERrER LozAno, "La cantería valenciana en la primera mitad del siglo XV", p. 99; - "El maestro de la catedral de Valencia Antoni Dalmau (act. 1435-1453)"; SERra Desfilis y Miquel JuAn, "La madera del retablo y sus maestros", p. 26.
} 
El análisis de la documentación demuestra una gran ambigüedad terminológica, que evidencia la falta de rigor, e incluso de desinterés, que la cultura medieval mostró hacia la semántica de los oficios de la construcción. El hombre medieval no aplicaba reglas absolutas para diferenciar a un arquitecto de un ingeniero, o de un creador de imágenes. Si la documentación no aclara donde se encontraban las fronteras entre los diferentes oficios artísticos, probablemente es porque éstas tampoco se encontraban demasiado definidas. Por tanto, debemos mostrar precaución, dado que al adentrarnos en este terreno nos enfrentamos a un panorama tan resbaladizo como fascinante, que es necesario comprender para acercarnos con rigor a la compleja realidad de la arquitectura gótica.

\section{Bibliografía}

Almuni Balada, Victòria, La catedral de Tortosa als segles del gòtic, Onada, Benicarló, 2007.

Alonso García, Gabriel, Los maestros de la Seu Vella de Lérida y sus colaboradores, Instituto de Estudios Ilerdenses, Lleida, 1976.

Alonso Ruiz, Begoña, "Los talleres de las catedrales góticas y los canteros del norte”, II Encuentro de historia de Cantabria, Jesús Ángel Solórzano y Manuel Ramón González, (eds.), Universidad de Cantabria, Santander, 2005, vol. II, pp. 707-728.

Alonso Ruiz, Begoña, "El maestro de obras catedralicio en Castilla a finales del siglo XV”, Anales de Historia del Arte, vol. 12, $\mathrm{n}^{\mathrm{o}}$ especial (2012), pp. 225-243.

Alonso Ruiz, Begoña, "Las trazas de montea en la construcción gótica: el caso de la montea de la Capilla Saldaña", Arquitectura tardogótica en la Corona de Castilla: trayectorias e intercambios, Begoña Alonso Ruiz y Fernando Villaseñor Sebastián, (eds.), Universidad de Cantabria - Secretariado de Publicaciones de la Universidad de Sevilla, Santander - Sevilla, 2014, pp. 329-344.

Alonso Ruzz, Begoña y Jiménez, Alfonso, La traça de la iglesia de Sevilla, Cabildo Metropolitano, Sevilla, 2009.

Argilés Aluja, Caterina, "Maestro Carlín en Cataluña", Magna Hispalensis: los primeros años, María del Carmen Álvarez Márquez, Aula Hernán Ruiz - Catedral de Sevilla, Sevilla, 2008, pp. 61-87.

BASSEgoda Nonell, Joan, "Projecte de la façana principal de la catedral de Barcelona", Thesaurus. Estudis: l'art als bisbats de Catalunya, 1000-1800, Jaume Barrachina (com.), Fundació Caixa de Pensions, Barcelona, 1986, pp. 172-173.

Bernaus, Magda, "Capítols, privilegis i ordinacions dels mestres de cases al final de l'edat mitjana", Le arti del costruire. Corporazioni edili, mestiere e regole nel Mediterraneo aragonese (XV-XVI secolo), Emanuela Garofalo (ed.), Caracol, Palermo, 2010, pp. 67-87. Bernaus, Magda, “"Mestres de Barcelona, experts en art»: la participación de maestros de Barcelona en la consulta de la catedral de Gerona (1386)", Obra Congrua, Enrique 
Rabasa Díaz, Ana López Mozo y Miguel Ángel Alonso Rodríguez (eds.), Instituto Juan de Herrera, Madrid, 2017, pp. 57-69.

Bonnassie, Pierre, La organización del trabajo en Barcelona a fines del siglo XV, Consejo Superior de Investigaciones Científicas, Barcelona, 1975.

Bracons Clapés, Josep y Terés Tomàs, Rosa, "La catedral de Barcelona", Arquitectura I. L'art gòtic a Catalunya, Antoni Pladevall Font (dir.), Enciclopèdia Catalana, Barcelona, 2002, pp. 274-301.

Carreras CAndi, Francesc: "Les obres de la catedral de Barcelona, 1298-1445", Butlletí de la Reial Acadèmia de Bones Lletres de Barcelona, vol. VII, 53 (1913-1914), pp. 302-317.

Cerdì Garriga, Magdalena, "Los Salort (1429-1523). Una familia de carpinteros en la Mallorca bajomedieval", Anuario de Estudios Medievales, 49/2 (2019), pp. 453-478.

Chamorro Trenado, Miquel Àngel, "La cofradía de los Cuatro Santos Mártires en el siglo XV", Le arti del costruire. Corporazioni edili, mestiere e regole nel Mediterraneo aragonese (XV-XVI secolo), Emanuela Garofalo (ed.), Caracol, Palermo, 2010, pp. 147-170.

Company, Ximo, L'art i els artistes al País Valencià Modern (1450-1600). Comportaments socials, Curial, Barcelona, 1991.

Coromines, Joan, Diccionari etimològic i complementari de la llengua catalana, Curial, Barcelona, 1986.

Domenge Mesquida, Joan, “Guillem Morey a la seu de Girona (1375-1397). Seguiment documental", Lambard. Estudis d'Art Medieval, 9 (1996), pp. 105-131.

Domenge Mesquida, Joan, L’obra de la seu. El procés de construcció de la catedral de Mallorca en el tres-cents, Institut d'Estudis Baleàrics, Palma de Mallorca, 1997.

Domenge Mesquida, Joan, "Le portail du Mirador de la Cathédrale de Majorque: du document au monument", Texte \& archéologie monumentale. Approches de l'architecture médiévale, Philippe Bernardi, Andreas Hartmann Virnich, Dominique Vingtain (dirs.), Monique Mergoil, Montagnac, 2005, pp. 10-26.

Domenge Mesquida, Joan, "Guillem Morei i l'activitat gironina”, Escultura I. L'art gòtic a Catalunya, Antoni Pladevall Font (dir.), Enciclopèdia Catalana, Barcelona, 2007, pp. 296-303.

Domenge Mesquida, Joan y Sureda Jubany, Marc, "Una o tres naus? Les consultes de 1386 i 1416 sobre la continuación de la catedral de Girona", Visurar l'obra gòtica: inspeccions, consells i reunions de mestres d'obra (s. XIV-XVIII), Joan Domenge Mesquida y Jacobo Vidal Franquet, Caracol, Palermo, 2017, pp. 77-117.

Domenge Mesquida, Joan y Vidal Franquet, Jacobo, “Construir i decorar un teginat: del document a l'obra", Quaderns de Museu Episcopal de Vic, 6 (2013), pp. 9-46.

Domenge Mesquida, Joan y Vidal Franquet, Jacobo, "«A coneixença de mestres experts». Les visures de l'obra gòtica a través de la documentació catalana", Visurar 
l'obra gòtica: inspeccions, consells i reunions de mestres d'obra (s. XIV-XVIII), Joan Domenge Mesquida y Jacobo Vidal Franquet, Caracol, Palermo, 2017, pp. 9-74.

Duran Sanpere, Agustí, Barcelona i la seva historia. Vol. III: L'art i la cultura, Curial, Barcelona, 1975.

Durliat, Marcel, "Un artiste picard en Catalogne et à Majorque: Pierre de SaintJean”, Caravelle, 1 (1963), pp. 111-120.

Español Bertrán, Francesca, "La transmisión del conocimiento artístico en la Corona de Aragón (siglos XIII-XIV)”, Cuadernos del CEMYR, 5 (1997), pp. 73-113.

FAlcón Márquez, Teodoro, El aparejador en la Historia de la arquitectura, Colegio Oficial de Aparejadores y Arquitectos Técnicos, Sevilla, 1981.

Fité Llevot, Francesc, “Los profesionales de la construcción en época medieval (siglos XIV-XV): Algunas cuestiones referidas al mundo hispánico y al territorio catalán", Ars et scientia. Estudios sobre arquitectos y arquitectura (s. XIII-XXI), Begoña Alonso Ruiz y Olatz Villanueva Zubizarreta, Castilla Ediciones, Valladolid, 2008, pp. 15-59.

FreiXas CAmps, Pere, L'Art gòtic a Girona (segles XIV $i X V$ ), Institut d'Estudis Catalans, Girona, 1983.

Galarza Tortajada, Manuel, "El maestro de obras en la Edad Media", Vida cotidiana en la España medieval. Actas del VI Curso de Cultura Medieval, María del Carmen Aguilera Castro (coord.), Fundación Santa María la Real, Aguilar de Campoo, 1998, pp. 343-357.

Gómez-Ferrer Lozano, Mercedes, "La cantería valenciana en la primera mitad del siglo XV: el Maestro Antoni Dalmau y sus vinculaciones con el área mediterránea”, Anuario del Departamento de Historia y Teoría del Arte, 9-10 (1997-1998), pp. 91-105.

Gómez-Ferrer Lozano, Mercedes (2007), "El maestro de la catedral de Valencia Antoni Dalmau (act. 1435-1453)", Academia.edu, https://www.academia.edu/11010998/EL_ MAESTRO_DE_LA_CATEDRAL_DE_VALENCIA_ANTONI_DALMAU_ACT.14351453_[29 septiembre 2019].

Gómez-Ferrer Lozano, Mercedes: El Real de Valencia (1238-1810). Historia arquitectónica de un palacio desaparecido, Institució Alfons el Magnànim, Valencia, 2012. Gómez-Ferrer Lozano, Mercedes y Zaragozá Catalán, Arturo, Pere Compte, arquitecto, Generalitat Valenciana, Valencia, 2007.

IbÁÑEz FernÁndez, Javier, "Con el correr del sol: Isambart, Pedro Jalopa y la renovación del Gótico final en la península Ibérica durante la primera mitad del siglo XV", El siglo XVI en la Ribera del Duero Oriental. Arte, Historia y Patrimonio, María Cruz Barahona y Pilar Rodríguez, (coords.), Ayuntamiento de Aranda de Duero, Aranda de Duero, 2011, pp. 201-226.

IBÁÑEZ FERnÁNDEZ, Javier, "Le corporazioni della costruzione nella Zaragoza del cinquecento", Le arti del costruire. Corporazioni edili, mestiere e regole nel Mediterraneo aragonese (XV-XVI secolo), Emanuela Garofalo (ed.), Caracol, Palermo, 2010, pp. 89-116. 
IBÁÑEZ FERNÁNDEZ, Javier, La capilla del palacio arzobispal de Zaragoza en el contexto de la renovación del Gótico final en la Península Ibérica, Museo Diocesano, Zaragoza, 2012. IBÁÑEZ FERnÁNDEZ, Javier, "The Northern Roots of Late Gothic Renovation in the Iberian Peninsula", Architects without Borders. Migration of Architects and Architectural ideas in Europe. 1400-1700, Konrad Ottenheym (ed.), Il Rio - Istituto Universitario Olandese di Storia dell'Arte, Mantua, 2014, pp. 15-27.

IBÁÑEZ FERnÁNDEZ, Javier (coord. y ed.), Trazas, muestras y modelos de tradición gótica en la Península Ibérica entre los siglos XIII y XVI, Instituto Juan de Herrera, Madrid, 2019.

IzQUIERdo ARANDA, Teresa, "Carpintero y maestro constructor en la arquitectura gótica valenciana (siglos XIV-XV)", Espacio, tiempo y forma. Serie VII: Historia del Arte, 1 (2013), pp. 199-221.

IzQUiERdo ArAnda, Teresa, La fusteria a la València medieval (1238- 1520), Universitat Jaume I, Castellón de la Plana, 2014.

IzQUIERDO ARANDA, Teresa, "Veedors, marquejadors, maestros: el valor de la experiencia en la carpintería medieval. El ejemplo valenciano", Anuario de Estudios Medievales, 44/2 (2014), pp. 885-910.

Jardí Anguera, Montserrat, “La intervenció d’Antoni Dalmau (†1453) a les galeries del claustre de la catedral de Barcelona”, Ars Longa. Cuadernos de Arte, 25 (2016), pp. 63-79.

JimÉnez MARTín, Alfonso, "Las fechas de las formas. Selección crítica de fuentes documentales para la cronología del edificio medieval", La catedral gótica de Sevilla. Fundación y fábrica de la Obra Nueva, Alfonso Jiménez (coord.), Universidad de Sevilla, Sevilla, 2006, pp. 15-114.

JimÉnez MARTín, Alfonso, "Los primeros años de la catedral de Sevilla: nombres, fechas y dibujos", Los últimos arquitectos del Gótico, Begoña Alonso Ruiz (coord.), M. Fernández-Rañada, Madrid, 2010, pp. 15-69.

JimÉnez Martín, Alfonso, Palabras de piedra. Primera aproximación al glosario gótico de la catedral de Sevilla, Aula Hernán Ruiz - Catedral de Sevilla, Sevilla, 2014.

JUAN ViCENS, Antònia, "El estatus social del artesano de la piedra a finales de la Edad Media. Un análisis sobre fuentes documentales mallorquinas", Medievalismo. Revista de la Sociedad Española de Estudios Medievales, 23 (2013), pp. 241-264.

JuAN ViCENS, Antònia, Lapiscida vel ymaginarius. L'art de la pedra a Mallorca a la baixa edat mitjana, Publicacions de l'Abadia de Montserrat, Barcelona, 2014.

LóPez LoRente, Víctor Daniel, La transmisión del saber técnico de los arquitectos en la Corona de Aragón en el tardogótico, Pagès, Lleida, 2019.

Llaguno y Amirola, Eugenio, Noticia de los arquitectos y arquitectura de España desde su restauración, Turner, Madrid, 1977 [1829]. 
Llompart, Gabriel, Miscelánea documental de pintura y picapedrería mallorquina, Govern de Les Illes Balears - Conselleria d'Educació i Cultura, Palma de Mallorca, 1999. Madurell Marimon, Josep Maria, "Les ordinacions de l'ofici de mestre de cases de Barcelona”, Butlletí del Centre Excursionista de Catalunya, vol. XLVII, 509 (1937), pp. 231-238.

MARIÑo, Beatriz, "La imagen del arquitecto en la Edad Media: Historia de un ascenso", Espacio, Tiempo y Forma. Serie VII, Historia del Arte, 13 (2000), pp. 11-25.

Martínez de Aguirre, Javier, "Calendario laboral, fiestas y primeras huelgas de constructores en la Navarra medieval (1346-1448)”, Príncipe de Viana, 216 (1999), pp. 145-190.

Martínez de Aguirre, Javier, "Investigaciones sobre arquitectos y talleres de construcción en la España medieval cristiana", Anales de Historia del Arte, vol. extraordinario (2009), pp. 127-164.

Miquel JuAn, Matilde, "Entre la formación y la tradición: Martí Lobet a cargo de las obras de la catedral de Valencia", Espacio, Tiempo y Forma. Serie VII, Historia del Arte, 22-23 (2009-2010), pp. 13-44.

Miquel JuAn, Matilde, "Martí Lobet en la catedral de Valencia (1417- 1439). La renovación del lenguaje gótico", Historia de la ciudad VI. Proyecto y complejidad, Málek Murad Mateu y Francisco Taberner (eds.), Colegio Territorial de Arquitectos de Valencia - Ayuntamiento de Valencia, Valencia, 2010, pp. 104-126.

Miquel Juan, Matilde, "Dibujo y diseño. La práctica de la pintura gótica", Ver y crear. Obradores y mercados pictóricos en la España gótica, Matilde Miquel Juan, Olga Pérez Mozón y Miriam Bueso Manzanas (eds.), La Ergástula, Madrid, 2016, pp. 15-41.

MONTERo TORTAJADA, Encarna, La transmisión del conocimiento en los oficios artísticos. Valencia, 1370-1450, Institució Alfons el Magnànim, Valencia, 2015.

Mortet, Victor, "La maîtrisse d'oeuvre dans les grandes constructions du XIII siècle et la profession d'appareilleur", Bulletin Monumentale, 70 (1906), pp. 263-270.

Muntaner Bujosa, Juan, "Partidas de gasto curiosas", Boletín de la Sociedad Arqueológica Luliana, 29 (1948), p. 365.

Muntaner Bujosa, Juan, "Piedra de Mallorca en el Castelnuovo de Nápoles", Boletín de la Sociedad Arqueológica Luliana, 31 (1960), pp. 615-630.

Ortoll Martín, Ernest, "Bernat Roca, un artífex pluridisciplinar”, L’Artista-artesà medieval a la Corona d'Aragó, Joaquín Yarza Luaces y Francesc Fité Llevot (eds.), Universitat de Lleida - Institut d'Estudis Ilerdencs, Lleida, 1999, pp. 279-293.

PAlomo, Gema, La catedral de Cuenca en el contexto de las grandes canterías catedralicias castellanas en la Baja Edad Media, Diputación de Cuenca, Cuenca, 2002.

Palou Sampol, Joana Maria, "Pere Morey, mestre major del portal del Mirador de la catedral de Mallorca", L'Artista-artesà medieval a la Corona d'Aragó, Joaquín Yarza Luaces y Francesc Fité Llevot (eds.), Universidad de Lleida - Institut d'Estudis Ilerdencs, Lleida, 1999, pp. 385-397. 
Palou SAmpol, Joana Maria, "Pere de Santjoan”, Escultura II. L'art gòtic a Catalunya, Antoni Pladevall Font (dir.), Enciclopèdia Catalana, Barcelona, 2007, pp. 84-90.

Pevsner, Nikolaus, “The Term 'Architect' in the Middle Ages”, Speculum, vol. 17, 4 (1942), pp. 549-562.

Ponz, Antonio, Viaje de España en que se da noticia de las cosas mas apreciables y dignas de saberse que hay en ella, Viuda de Ibarra, Hijos y Compañía, Madrid, 1788. Rada y Delgado, Juan de Dios, Viaje de SS. MM. y AA, por Castilla, León, Asturias y Galicia en el verano de 1858, Aguado, Madrid, 1860.

Recht, Roland, Les bâtisseurs des cathédrales, Seuil, París, 1980.

Recht, Roland (1980), “Les termes techniques de l'architecture médiévale", Histoire et Archéologie, 47 (1980), pp. 84-90.

Rubio SAmper, Jesús Miguel, "La figura del arquitecto en el período gótico. Relaciones entre España y el resto de Europa", Boletín del Museo e Instituto Camón Aznar, 22 (1985), pp. 101-115.

SÁnchez Verduch, María del Mar, "Maestros de obras en la Valencia gótica: personajes polifacéticos", Saitabi, 48 (1998), pp. 273-288.

SAnchis Sivera, Josep, "La escultura valenciana en la Edad Media: notas para su historia", Archivo de arte valenciano, 10 (1924), pp. 3-29.

SAnchis Sivera, Josep, "Maestros de obras y lapicidas valencianos en la Edad Media", Archivo de arte valenciano, 11 (1925), pp. 23-52.

Serra Desfilis, Amadeo, “Al servicio de la ciudad: Joan del Poyo y la práctica de la arquitectura en Valencia (1402-1439)", Ars Longa. Cuadernos de Arte, 5 (1994), pp. 111-119.

Serra Desfilis, Amadeo y Miquel Juan, Matilde, "Pere Balaguer y la arquitectura valenciana entre los siglos XIV y XV", Historia de la ciudad IV: memoria urbana, Málek Murad Mateu y Francisco Taberner (eds.), Colegio Territorial de Arquitectos de Valencia - Ayuntamiento de Valencia, Valencia, 2005, pp. 90-111.

Serra Desfilis, Amadeo y Miquel Juan, Matilde, "La madera del retablo y sus maestros. Talla y soporte en los retablos medievales valencianos", Archivo de arte valenciano, 91 (2010), pp. 13-37.

Serra RÀfols, Elies, "La nau de la seu de Girona", Miscel-lània Puig i Cadafalch: recull d'estudis d'arqueologia, d'història de l'art i d'història, Ramon Aramon Serra, Josep de C. Serra Ràfols, Ricard Albert Llauró y Miquel Coll Alentorn (coords.), Institut d'Estudis Catalans, Barcelona, 1947-1951, vol. I, pp. 185-204.

SigüEnZA, José de, Fundación del Monasterio de El Escorial, Aguilar, Madrid, 1963.

Terés TomÀs, Rosa, “Arnau Bargués, arquitecto de la ciudad de Barcelona: nuevas aportaciones documentales", Boletín del Instituto y Museo Camon Aznar, 9 (1982), pp. 72-86. Terés Tomàs, Rosa, "Pere de Sant-Joan, i el Mestre de la cadira episcopal de Barcelona. Hipòtesi sobre una identitat", Quaderns d'Estudis Medievals, 23-24 (1988), pp. 32-51. 
Terés TomÀs, Rosa, “Obres del segle XV a la Catedral de Barcelona. La construcció de l'antiga sala capitular", Lambard. Estudis d'Art Medieval, 6 (1991-1993), pp. 389-413. Terés TomÀs, Rosa, “Antoni Canet, un artista itinerant a la catedral de Barcelona”, $D$ ' Art: Revista del Departament d'Historia de l'Arte, 19 (1993), pp. 65-84.

Terés TomÀs, Rosa, "Les obres de la catedral de Barcelona i la intervenció de Francesc Marata, un escultor del gòtic internacional”, Barcelona quaderns d'història, 8 (2003), pp. 201-231.

Terés TomÀs, Rosa, “Antoni Canet, arquitecte i escultor” Escultura II. L'art gòtic a Catalunya, Antoni Pladevall Font (dir.), Enciclopèdia Catalana, Barcelona, 2007, pp. pp. 62-73.

Terés TomÀs, Rosa, “Arnau Bargués i els seus escultors”, Escultura II. L'art gòtic a Catalunya, Antoni Pladevall Font (dir.), Enciclopèdia Catalana, Barcelona, 2007, pp. 74-81. Terés TomÀs, Rosa, “Arnau Bargués (c. 1374-1413)”, Gli ultimi indipendenti. Architetti del gotico nel Mediterraneo tra XV e XVI secolo, Emanuela Garofalo y Marco R. Nobile (eds.), Caracol, Palermo, 2007, pp. 23-46.

Valero Molina, Joan, “L'etapa gironina de l'escultor Pere de Santjoan”, Annals de l'institut d'Estudis Gironins, 42 (2001), pp. 221-236.

VAlero Molina, Joan, "El projecte de la portalada major de la catedral de Barcelona. El mestre Carlí i el seu entorn professional", Ianua coeli. Portalades gòtiques a la Corona d'Aragó, Francesca Español y Joan Valero (coords.), Institut d'Estudis Catalans, Barcelona, 2020, pp. 217-258.

VERrié, Frederic Pau, "Un arquitecto en la Barcelona medieval. Arnau Bargues y sus obras", Barcelona: divulgación histórica. Textos radiados desde la emisora de «Radio Barcelona» por el Instituto Municipal de Historia de la Ciudad, Agustí Duran i Sanpere, Aymà, Barcelona, 1947, vol. IV, pp. 146-152.

VICtor, Sandrine, La construcció $i$ els seus oficis a la Girona del segle XV, Ajuntament de Girona, Girona, 2004.

Victor, Sandrine, "La mà d'obra", Sintesi general, índex generals. L'art gòtic a Catalunya, Antoni Pladevall Font (dir.), Enciclopèdia Catalana, Barcelona, 2009, pp. 207-209.

Vidal Franquet, Jacobo, "Pere Compte, mestre major de l'obra de la Seu de Tortosa", Anuario de estudios medievales, 35/1 (2005), pp. 403-431.

Vidal Franquet, Jacobo, "Una obra d' Antoni Queralt a cavall de Lleida i Tortosa", Urtx: Revista cultural de l'Urgell, 20 (2007), pp. 126-155.

VidAl Franquet, Jacobo, "Sobre la personalitat i l'activitat de Joan de Frenoy. Apunts", El trecento en obres. Art de Catalunya i art d'Europa al segle XIV, Rosa Alcoy (ed.), Universidad de Barcelona, Barcelona, 2009, pp. 397-407.

VidAl FrAnQuet, Jacobo, “L'activitat quotidiana d'un mestre de cases medieval. Bernat Gual, 1405-1453”, Anuario de estudios medievales, 43/2 (2013), pp. 915-940. 
Vidal Franquet, Jacobo, "Bernat Gual, mestre de cases de la ciutat de Tortosa. Seguiment documental", Recerca, 17 (2017), pp. 207-235.

Yarza Luaces, Joaquín, “Artista-artesano en el gótico catalán I", Lambard. Estudis d'Art Medieval, 3 (1983-1985), pp. 129-169.

YARZA LuACES, Joaquín, "El artista gótico hispano", I Curso de cultura medieval, Francesc Xavier Mingorance y Ricart (coord.), Centro de Estudios del Románico, Aguilar de Campoo, 1989, pp. 29-43.

YARZA Luaces, Joaquín, “Artistes-artisans de la Couronne de Castille au temps des Rois Catholiques. Aspects économiques et professionnels", Razo, 14 (1993), pp. 143-156.

YARZA Luaces, Joaquín, “Artista-artesano en la Edad Media hispana”, L'Artista-artesà medieval a la Corona d'Aragó, Joaquín Yarza Luaces y Francesc Fité Llevot (eds.), Universidad de Lleida - Institut d'Estudis Ilerdencs, Lleida, 1999, pp. 7-58.

Yarza Luaces, Joaquín (ed.), Arte Medieval II: Románico y Gótico (Fuentes y documentos para la Historia del Arte), Gustavo Gili, Barcelona, 1982. 